Some Effects of Employment Centers on Commuting Times in the Atlanta Metropolitan $\underline{\text { Area, } 1990}$

By: Selima Sultana

Sultana, S. (2000) "Some Effects of Employment Centers on Commuting Times in the Atlanta Metropolitan Area, 1990," Southeastern Geographer, Vol. 41, No. 2, pp. 225-233.

Made available courtesy of the University of North Carolina Press: https://doi.org/10.1353/sgo.2000.0020

From Southeastern Geographer, Volume 41 and Pages 225-233. Copyright $\mathbb{C} 2000$ by the University of North Carolina Press. Used by permission of the publisher. https://www.uncpress.org

***Note: No further reproduction is authorized without written permission from the University of North Carolina Press.

\begin{abstract}
:
This study examines the relationship between one-way commuting time to major employment clusters in the Atlanta metropolitan area in 1990 and (1) the employment size of the clusters, (2) their distance from the major CBD cluster, and (3) selected attributes of workers in these clusters. The clusters are divided into centers and subcenters and central area and suburban locations. In addition to analyzing descriptive data, seven independent variables were correlated with mean commuting time in order to test three sets of hypotheses. Data are from the 1990 U.S. Census of Transportation Planning Package for a 13-county portion of the Atlanta metropolitan area, and utilize 948 Transportation Analysis Zones. It was found that three sets of factors are associated with mean commuting time: In order of importance they are distance of the cluster from the CBD (inverse association); characteristics of the workforce in the cluster, viz.

percentage of high-income workers, percentage of workers who are Black, and percentage of transit users; and employment size of the cluster.
\end{abstract}

Keywords: commuting | employment clusters | Atlanta

Article:

$* * *$ Note: Full text of article below 


\title{
SOME EFFECTS OF EMPLOYMENT CENTERS ON COMMUTING TIMES IN THE ATLANTA METROPOLITAN AREA, 1990
}

\begin{abstract}
Selima Sultana
This study examines the relationship between one-way commuting time to major employment clusters in the Atlanta metropolitan area in 1990 and (1) the employment size of the clusters, (2) their distance from the major CBD cluster, and (3) selected attributes of workers in these clusters. The clusters are divided into centers and subcenters and central area and suburban locations. In addition to analyzing descriptive data, seven independent variables were correlated with mean commuting time in order to test three sets of hypotheses. Data are from the 1990 U.S. Census of Transportation Planning Package for a 13-county portion of the Atlanta metropolitan area, and utilize 948 Transportation Analysis Zones. It was found that three sets of factors are associated with mean commuting time: In order of importance they are distance of the cluster from the CBD (inverse association); characteristics of the workforce in the cluster, viz. percentage of high-income workers, percentage of workers who are Black, and percentage of transit users; and employment size of the cluster.
\end{abstract}

Key words: commuting, employment clusters, Atlanta.

INTRODUCTION. Most studies of the intraurban journey to work assume that urban spatial structure strongly affects commuting length and pattern (Hodge, 1992; Giuliana and Small, 1993; Levinson and Kumar, 1994; Merriman et al., 1995). It has now long been recognized that urban spatial structure has changed from a monocentric to a polycentric pattern over the last four decades (Gordon et al., 1989; Clark and Kuijpers-Linde, 1994; Fujii and Hartshorn, 1995; Levinson and Kumar, 1994). As a result, studies show polycentric models statistically explain today's spatial distribution of population and employment much better than do the outdated monocentric models (Gordon et al., 1989; Small and Song, 1992; McDonald and Prather, 1994). The emergence of multiple centers of economic activities in U.S. metropolitan areas has raised questions as to whether the changing urban structure from the monocentric model to a multinucleated pattern has increased commuting length. There appears to be no clear answer. Some have found dispersed employment decreases commuting length (Gordon et al., 1989; 1991; Suh, 1990; Dubin, 1991; Giuliano and Small, 1993; Levinson and Kumar, 1994) because suburbanization of jobs have brought workers close to their home and away from the centralcity congestion. Others have argued that dispersal increases the commuting length and time because of more cross-town suburb-to-suburb trips (Hamilton, 1982; Bookout, 1992; Downs, 1992; Hughes, 1992; Hu and Young, 1992; Rosetti and Eversole, 1993). Using the large geographic scale data provided by the 1990 U.S. Census of Transportation Planning Package (CTPP), this study analyzes empirically

Dr. Sultana is an Assistant Professor in the Department of Geography and Geology, Auburn University, Auburn, AL 36849.Internet: sultase@auburn.edu. 
the relationships between the metropolitan spatial structure of Atlanta and mean commuting time to major employment centers and subcenters.

PURPOSE AND HYPOTHESES. The purpose of this paper is to examine relationships between employment clusters and mean one-way commuting times to these clusters for the Atlanta metropolitan area for 1990. Three hypotheses are advanced: (1) the higher the absolute employment in a cluster, the greater will be the mean journey to work to reach that cluster; (2) employment clusters located centrally will have higher mean commuting times than suburban clusters; and (3) selected worker attributes of employment clusters will exist independently from commuting time for clusters of different size. The processes underlying these hypotheses-employment size, centrality, and a cluster's worker attributes--of course operate simultaneously.

DATA AND STUDY AREA. This analysis uses detailed journey-to-work data from the 1990 U.S. Census of Transportation Planning Package (CTPP). Data are provided at a high level of geographical resolution, by Transportation Analysis Zones (TAZs), and are organized in three ways by type of person surveyed. The first part of the CTPP has data by place of residence, the second part contains place-of-work data, and the third part provides origin-destination data $(\mathrm{O}-\mathrm{D})$ and one-way mean travel time for each O-D pair (by mode). Data from the first and second parts of the CTPP databases are used in this research. The first part of the CTPP data provides residence characteristics and commuting time. The second part of the CTPP data provides information on workers such as location of employment and characteristics of the worker. For each jurisdiction (TAZ), data are given on how many workers are employed in each jurisdiction and the average time spent commuting. The geographical data (polygon files) of TAZs in this study were collected from the Atlanta Regional Commission (ARC), a 10-county planning agency. There were $948 \mathrm{TAZs}$ in Atlanta region in 1990.

The 13 counties of Atlanta region, one of the most traffic-congested regions in the United States (Cervero, 1989), was selected for this study. Since the CTPP data are not available for all 20 counties of the U.S. Census-defined Atlanta metropolitan area, only 13 counties of the Atlanta region in 1990 are examined (Fig. 1). This Atlanta region, containing 1.65 million people and 1.40 million jobs in 1990 , is well known for its sprawl and its suburban employment centers.

CRITERIA FOR IDENTIFYING CENTERS AND SUBCENTERS In order to analyze the functions and distribution of clusters and their associated commuting patterns, I identified the location of employment: CBD-Midtown, 10 centers, and 40 subcenters in the Atlanta metropolitan area. Various methods have been used to define metropolitan centers and subcenters in the past. I used employment concentration to define centers by utilizing small areal units (smaller than block groups), transportation analysis zones (TAZs). Defining an employment center should be 


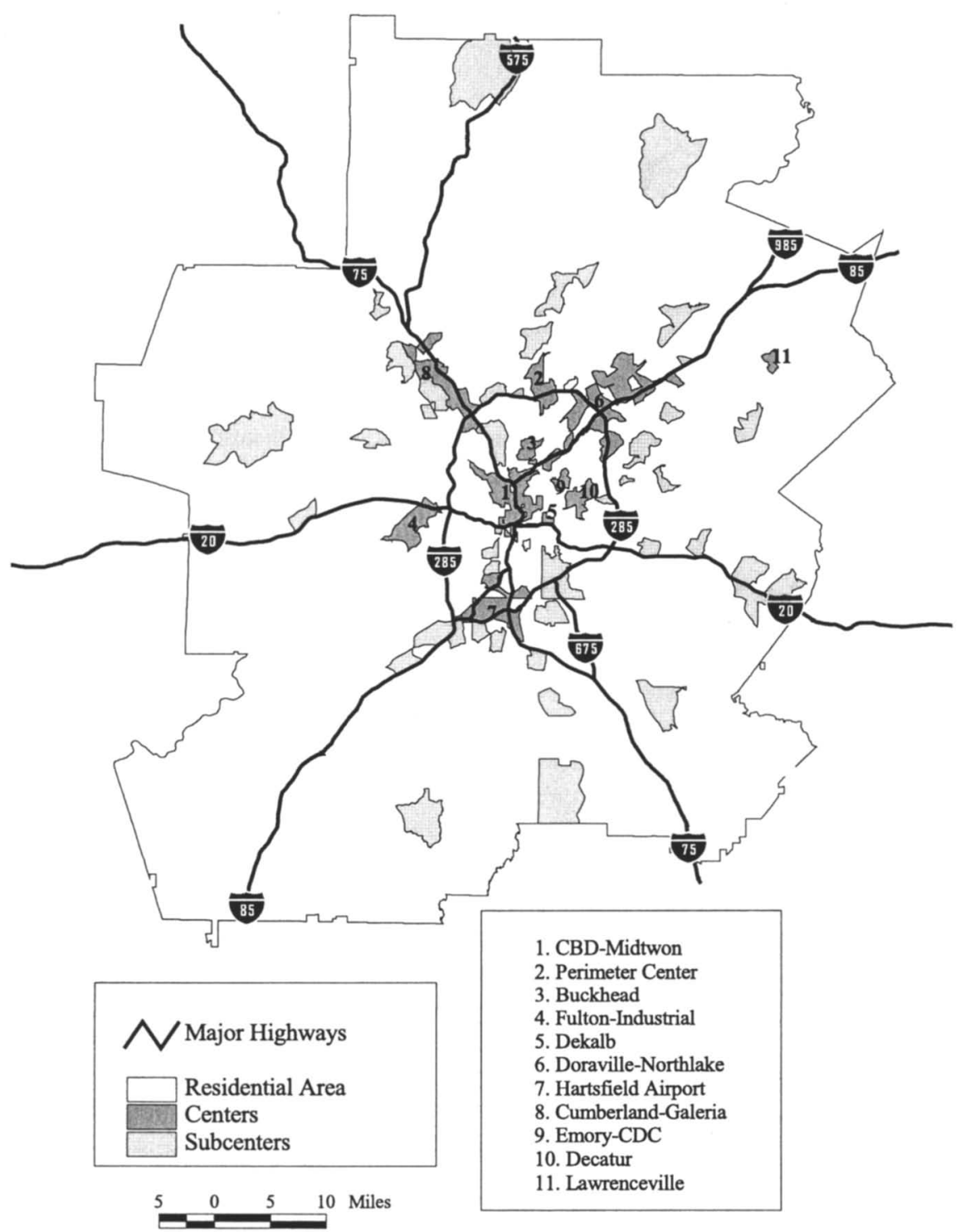

Fig. 1. The location of employment centers and subcenters in the Atlanta metropolitan area, 1990. 
TABLE 1

MEAN COMMUTING TIME BY EMPLOYMENT CLUSTERS AND LOCATION IN THE ATLANTA METROPOLITAN AREA, 1990 (in minutes one-way)

\begin{tabular}{lcccc}
\hline \hline \multicolumn{1}{c}{ Area } & CBD-Midtown & Centers $^{b}$ & Subcenters & Total \\
\hline Central Area ${ }^{b}$ & 31.69 & $29.00(2.40)^{c}$ & $30.00(2.44)$ & $29.90(2.37)$ \\
Suburbs & NA & $27.44(3.33)$ & $24.00(2.85)$ & $24.54(3.14)$ \\
Metropolitan Area & 31.69 & $28.10(2.90)$ & $25.04(3.58)$ & $27.71(3.64)$ \\
\hline
\end{tabular}

a 13 -county study area.

'Locations inside $\mathrm{l}-285$.

'Standard deviations in parentheses.

Source: U.S. Census of Transportation Planning Package data.

based on two criteria: a density threshold and a minimum (absolute) employment total (Giuliano and Small, 1993; Cervero and Wu, 1997; Wang, 2000). One criterion for identifying an employment center is a contiguous set of TAZs, each with an employment density above four workers per acre. The second criterion is that the combined TAZs of a center must sum to at least 10,000 workers. However, in the outer boundary if the total employment is equal to 7,000 , it is considered a center even if it does meet the density criterion. The CBD-Midtown area stands as Atlanta's premier employment center and constitutes its own unique center status.

To identify a subcenter two criteria were followed: (1) if density criteria are met, but employment totals are not sufficient, or vice versa, a group of zones or a single zone will be considered a subcenter; (2) a subcenter can be defined as a zone whose measure of employment concentration is higher than all adjacent zones. For that measure gross employment density or employment/population is used to identify a subcenter.

MEAN ONE-WAY COMMUTING TIMES BY EMPLOYMENT CLUSTERS. When the 13-county Atlanta metropolitan study area is broken into three categories of employment clusters (CBD-Midtown, other centers, and subcenters), it is first clear that one-way mean commuting times are greatest for travel to the CBD-Midtown area (Table 1). Second, it is also clear that commuting to suburban employment centers and subcenters is shorter on average than commuting time to centers and subcenters in the central area (within I-285). Third, commuting time to subcenters is shorter than to centers for the metropolitan area as a whole. Thus, more dispersed employment clusters have commuting advantages over more centrally located clusters and smaller employment clusters have lower average commuting times than larger centers for the study area as a whole. Both findings support the first two hypotheses of this study. Figure 2 shows the percentage of workers commuting to the CBD-Midtown area, to the 10 centers, and to the 40 subcenters by one-way 


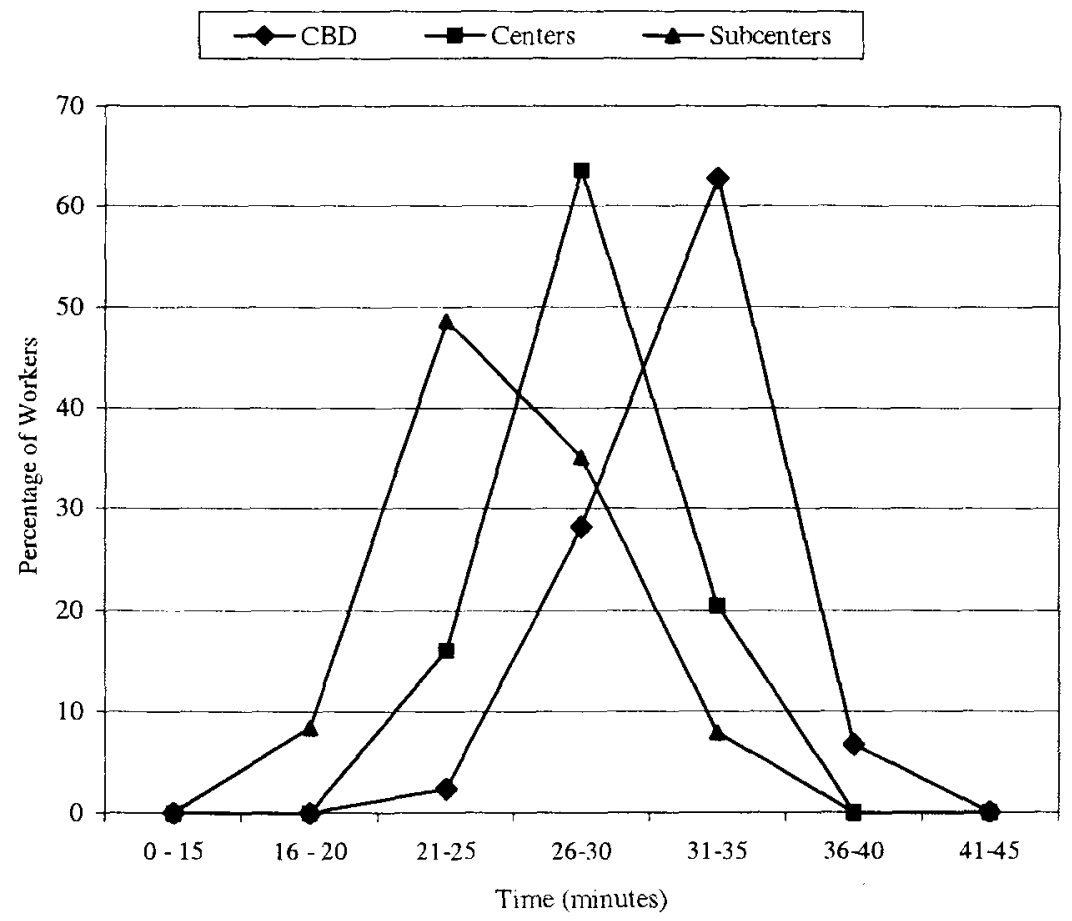

Fig. 2. The relationship between mean commuting time and the percentage of workers employed in the CBD, centers, and subcenters in the Atlanta metropolitan area, 1990.

travel time. It is apparent that trips to the CBD-Midtown area has a longest mean commuting time. This area also has the largest average range of commute, between a maximum of 41-45 minutes versus a relatively short 16-20 minutes. An equally long range of mean commuting time is reflected by subcenters ( $0-15$ and $36-40$ minutes), but these subcenters have a much lower overall mean. The 10 centers have the smallest average range and an intermediate overall mean commuting time.

Table 2 shows the variations in mean commuting time for the 11 employment centers (Table 2). Five centers have averages well above the metropolitan mean of 27.71 minutes, with only the Perimeter Center lying largely outside I-285. Lawrenceville, in suburban Gwinnett County, has the lowest mean commuting time. Lawrenceville and Decatur, with the two lowest means, also have the fewest numbers of workers, 11,550 and 10,840, respectively. By contrast, 242,170 people work in the CBD-Midtown area.

Of the forty subcenters, East Point has the longest average commute, 34 minutes. The East Point subcenter has a high density of employment and is located in 
TABLE 2

ZERO-ORDER CORRELATION COEFFICIENTS BETWEEN MEAN COMMUTING TIME AND SELECTED VARIABLES

\begin{tabular}{lccc}
\hline \multicolumn{1}{c}{ Variables } & \multicolumn{3}{c}{ Pearson correlation coefficients } \\
\cline { 2 - 4 } & Centers & Subcenters & Total \\
\hline Structural variables: & .45 & .01 & .34 \\
$\quad$ Total employment & .36 & .41 & .46 \\
Employment density & -.79 & -.66 & -.71 \\
Distance from CBD & -.26 & -.64 & -.58 \\
Central area/suburbs & & & \\
Cluster attributes: & .57 & .57 & .60 \\
Pct. of workers $>$ \$50,000 per year & .49 & .46 & .49 \\
Pct. of Black workers & .48 & .60 & .31 \\
Pct. of workers using public transit & 11 & 40 & 51 \\
$N \quad$ &
\end{tabular}

Source: Calculated by author from U.S. Census of Transportation Planning Package data.

the central area. Other subcenters to which commuting time is more than 30 minutes are all located in the central area and close to high-density areas. In almost all cases, commuting times for suburban subcenters are shorter than 30 minutes, with the lowest commuting time being 19 minutes to Douglasville subcenter.

CORRELATES OF COMMUTING. Seven independent variables were hypothesized to correlate with the overall variations in one-way mean commuting time (Table 2). Two variables, total employment and employment density of clusters, are used to measure employment, as discussed above. Two variables, distance from CBD and a dichotomous central area/suburban index, are used to measure the effect of location, also discussed above. These four variables are referred to as structural variables, as they attempt to appraise the role of Atlanta's spatial structure. Whereas the employment variables are expected to have a positive correlation with mean community time, the dependent variable, the latter two variables are anticipated to show a negative relationship.

Three additional variables, here termed cluster attributes, are identified, based on previous studies of the urban journey to work. Since most studies have shown that higher-income workers travel farther to work on average than lower-income employees, the percentage of workers with an annual income in 1990 of more than $\$ 50,000$ at each center and subcenter was used to account for mean commuting time. Likewise, most studies have found that African Americans, especially when concentrated residentially in central-city locations, have to travel farther, on 
average, than Whites to find jobs in the suburbs. Consequently, the percentage of Blacks working in each center and subcenter is used to correlate with mean commuting time to that employment cluster. The third cluster attribute variable is the percentage of workers using public transit (MARTA rail and buses), with the expectation that public transit users would have longer average journeys to work. All of the attribute variables, percentage high income, percentage Black, and percentage transit users are expected to have positive signs in the correlations with the dependent variable. Thus, these seven independent variables were calculated separately for employment centers and subcenters and for centers and subcenters combined (total).

Statistically significant zero-order Pearson correlation coefficients were found among almost all the seven independent variables with mean commuting time for all three separate sets of calculations (Table 2). The strongest overall correlation was for distance from the CBD $(r=.71)$ and the weakest with percentage of workers using public transit (.31), the latter value probably being attributed to the low proportion of total workers using public transit. The dicotomous central area/suburban variable was less discriminating that the more precise variable, distance from $\mathrm{CBD}$, especially for employment centers, although they were almost equal for employment subcenters. The two employment variables show lower correlations with commuting times than expected, particularly for subcenters. Percentage of high-income workers showed a slightly stronger correlation with travel time than the percentage of Black workers, though both attribute variables were significant for all three sets of calculations.

These correlation findings offer support, though weak, in favor of the first hypothesis that longer mean commuting will be associated with large employment clusters. The notable exception is the lack of a relationship between total employment and commuting for subcenters, which may be attributed in part to the fact that subcenters, by definition, are small employment clusters. The role of location, specifically distance from the CBD, however, shows considerable support for the second hypothesis; the third hypothesis, relating to cluster attributes, finds the strongest support for the longer commuting times to clusters employing the highest percentage of high-income workers. Likewise, clusters having a high percentage of Black workers experience a long mean commuting time, whereas those clusters employing a high percentage of transit users show a somewhat weaker positive relationship with longer travel times. In sum, general validation is found for each of the three hypotheses based on zero-order Pearson correlation coefficients.

CONCLUDING COMMENTS. This study, based on mean commuting time for a 13-county area of the Atlanta metropolitan region using 1990 data, finds support for the argument that a spatially dispersed employment pattern leads to a shorter journey to work than a more centralized concentration of jobs, as commuting to suburban employment clusters averages less to than centrally located clusters. Whereas 
Atlanta has extremely long commuting times compared with other U.S. metropolitan areas and hence terrific traffic congestion during rush hours, the dispersed pattern of suburban centers and subcenters in Atlanta offers a less onerous traffic outcome than one based on a greater concentration of centrally located jobs. Three sets of factors contribute to mean commuting time. In order of importance, they are distance from the $\mathrm{CBD}$, with its tremendous density of employment; characteristics of the workforce in the job clusters (e.g., percentage of high-income workers, percentage Black, and percentage transit users); and employment totals within clusters.

\section{LITERATURE CITED}

Bookout, L. 1992. "Neotraditional Town Planning: Cars, Pedestrians, and Transit," Urban Land, Vol. 51, pp. 10-15.

Cervero, R. 1989. "Jobs Housing Balancing and Regional Mobility," Journal of the American Planning Association, Vol. 55, pp. 136-150.

Cervero, R. and Wu, K. 1997. "Polycentricism, Commuting, and Residential Location in the San Francisco Bay Area," Environmental and Planning A, Vol. 29, pp. 865-886.

Clark, W. A. V. and Kujjpers-Linde, M. 1994. "Commuting in Restructuring Urban Regions," Urban Studies, Vol. 31, pp. 465-483.

Downs, A. 1992. Stuck in Traffic: Coping with Peak Hour Traffic Congestion (Washington DC: The Brookings Institution).

Dubin, R. 1991. "Commuting Patterns and Firm Decentralization," Land Economics, Vol. 67, pp. 15-29.

Fujii, T. and Hartshom, T. A. 1995. "The Changing Metropolitan Structure of Atlanta, Georgia: Location of Functions and Regional Structure in Multinucleated Urban Area," Urban Geography, Vol. 16, pp. 680-707.

Giuliano, G. and Small, K. A. 1991. "Subcenters in the Los Angeles Region," Regional Science and Urban Economics, Vol. 21, pp. 163-182.

Giuliano, G. and Small, K. A. 1993. "Is Journey to Work Explained by Structure?" Urban Studies, Vol. 30, pp. 1485-1500.

Gordon, P. H. W. 1989. "The Influence of Metropolitan Spatial Structure on Commuting Time," Journal of Urban Economics, Vol. 26, pp. 138-151.

Gordon, P. and Jun, M. 1991. "The Commuting Paradox: Evidence from the Top Twenty," Journal of the American Planning Association, Vol. 57, pp. 416-420.

Gordon, P., Richardson, H. W., and Wong, H. L. 1989. "The Distribution of Population and Employment in a Polycentric City: The Case of Los Angeles," Environment and Planning $A$, Vol. 18, pp. 161-173.

Hamilton, B. C. 1982. "Wasteful Commuting," Journal of Political Economy, Vol. 90, pp. 1035-1053.

Hodge, D. C. 1992. "Urban Congestion: Reshaping the Urban Life," Urban Geography, Vol. 13, pp. 577-588.

Hughes, M. 1992. "Employment Decentralization and Accessibility: A Strategy for Stimulating Regional Mobility," Journal of the American Planning Association, Vol. 58, pp. 288299. 
Hu, P. and Young, J. 1992. Summery of Travel Trends: 1990 Nationwide Personal Transportation Survey (Washington, DC: Federal Highway Administration).

Levinson, D. M. and Kumar, A. 1994. "The Rational Locator: Why Travel Times Have Remained Stable," Journal of the American Planning Association, Vol. 60, pp. 319-333.

McDonald, J. F. and Prather, P. J. 1994. "Suburban Employment Centers: The Case of Chicago," Urban Studies, Vol. 31, pp. 201-218.

Merriman, D., Ohkawara, T. and Suzuki, T. 1995. "Excess Commuting in the Tokyo Metropolitan Area: Measurement and Policy Simulations," Urban Studies, Vol. 32, pp. 69-85.

Rosetti, M. and Eversole, B. 1993. Journey to Work Trends in the United States and its Major Metropolitan Areas (Cambridge, MA: John A Volpe National Transportation System Center).

Small, K. A. and Song, S. 1992. "Wasteful Commuting: A Resolution," Journal of Political Economy, Vol. 100, pp. 888-898.

Suh, H. 1990. "Wasteful Commuting: An Alternative Approach," Journal of Urban Economics, Vol. 28, pp. 277-286.

Wang, F. 2000. "Modeling Commuting Patterns in Chicago in a GIS Environment: A Job Accessibility Perspective," Professional Geographer, Vol. 52, pp. 120-133. 